\title{
Feasibility Study on the Fusion of Traditional Art Teaching and New Media Art Teaching
}

\author{
Li Zhang ${ }^{1}$ \\ ${ }^{1}$ Wuhan Textile University, College of Art and Design, Wuhan, Hubei, 430073
}

\begin{abstract}
KEYWORDS: Traditional Art Teaching; New Media Art Teaching; Fusion; Feasibility
\end{abstract}
\begin{abstract}
New media" refers to the use of computers (computing and information processing) and network (dissemination and exchange) and other new technology on the form, content and type of traditional media fusion widen so that it occurs a new information medium qualitative change form, but also said fourth media. That is a new form of media in the strong impact of the new movement in art brings formed, the new concept of "optics" and electronic media as the basic language of the new artistic disciplines. Integration of new media art teaching traditional arts teaching the emergence of many new ways of thinking and teaching, which are in our country in recent years to increase the popularity of traditional art teaching "new media art" performance results. Phenomena indicates that China in the future will be more traditional art teaching more widely popular "new media art."
\end{abstract}

\section{Introduction}

Integration of new media art in the traditional art of teaching the emergence of many new ways of thinking and teaching - rich on new media art theory class theoretical knowledge; a wide selection of digital art works appreciation on appreciation course; practical classes for teachers and students various types of digital art works produced; big game more and more high school digital art. These are our country in recent years to increase the popularity of traditional art teaching "new media art" performance results. Phenomena indicates that China in the future will be more traditional art teaching more widely popular "new media art."

As China's traditional art teaching more and more integrated into the new media art element, most high school art teachers are familiar with how to use the "new media art" to achieve teaching objectives, but poor in the study "new media art" fusion of traditional arts teaching many of the root causes of the problem. Study author extracted data from the effective teaching practice and research in art and culture, a macro perspective to elaborate the "new media art" to bring some changes in the traditional art of teaching. But also as a starting point to explore the major trends in the "new media art" in the traditional art of teaching integration. More "new media art" integration in Outlook traditional art teaching some change.

"New media art" as an integrative discipline, it does not exclude the traditional art, while learning from the advantages of the traditional art of being fused to their own development. It is also more and more people accept the "new media art" reasons. When we lament the rapid economic development, accelerate the pace of society, while marching to the beat of new media art into the information age, we know the traditional art of teaching.

\section{The Concept of New Media Art Teaching}


From the 1980s, the "AVE" 2011 will be the "new media art" introduced the concept of "compulsory art class standard" for the first time, China's traditional art teaching new media art component only slightly shape. For this reason, the current traditional art teaching new media art is not possible to accept the whole discipline overall, it should be introduced into some of the most basic, the most common and most easily accepted form and ideas.

After several changes after the now traditional art teaching system has covered include: digital graphic arts, web art and interactive multimedia art section. These categories is the new media arts in the audience the most, the most extensive coverage in the form of art as well as traditional art teaching easiest art forms operate and practice, new media art concepts involved in this article is also included in this range can be said to be a relative to the traditional art of teaching, as well as part of the system to be included in the future development of middle school art, new media art is a narrow concept.

\section{The Complementarity of New Media Art and Traditional Art Aesthetic}

To express the meaning of art is neither a simple reflection of certain claims, nor is it in advance examines the validity of the theory. Essential function of art is to describe in detail the real existence, informative and practical content. This process can also be viewed as a process of dialogue, or emotional resonance after the course produced, or some means of thinking and consciousness into some of the tangible and intangible formal process. From one side, the new media art in itself transcends the concept of art. From the content of the performance and expression formal point of view, new media art and traditional arts in the form of different, it does not require any real substance dependence, is a non-material, can only be the time to judge, sublimation traditional aesthetic guidelines, creating a virtual field of aesthetic categories. "

Each designer of visual communication design, not only to the scientific understanding of the design is science commercialization support this feature, but also to make clear that they are aware of science and technology into reality intermediary entities. " Today, the human use of digital media design approach allows the dissemination of information beyond the limits of the geographical, cultural, time, so that the speed and efficiency of information dissemination have a new change. But no matter how to change the way information dissemination, new media art design, visual design elements are still important basic elements, you must rely on it to achieve the purpose of disseminating information. Therefore, the new media art and design and advertising design, book decoration, costume design and so the traditional design also belongs to the same category of visual communication Category design. The new media art and design as a visual design to develop a new design category created after the information society, it is bound to adapt to the various features of the visual flow, and thereby forming various visual media art design elements links between. This surprises with new media art design and the traditional art and design as visual aesthetic to follow certain rules, and guidance and impart information is generated by a change in vision. It complete and accurate visual media carrier to convey information is the core of all digital design categories have to face, it also means that these categories have followed a common aesthetic criteria.

\section{The Specific Programs of Fusing New Media Art Education into Traditional Art Teaching}

First, the visual image of the perception, understanding, and create a focus for the students about the ideas of art expression, attitudes and aesthetic taste, and enrich students' social and natural sciences knowledge to enable students to meet the spiritual in the curriculum and the dual demands of the material world; secondly, professor conveyed by the image and communication methods to form the 
awareness of new media art, so that students learn the art of the human spirit, students sense of the modern aesthetic tastes and art literacy; and finally, from the "vision "of" practical "started to teach students how to use new media to create works of students of imagination, practical ability, creativity while developing their imagination, the image of thinking, expression and communication skills.

New media art is non-traditional art forms, but it occupies a pivotal position in modern art. It is a departure from the traditional arts, advocated a new form of new standards advocated. Science and technology to make art more fascinating new forms of context and atmosphere in the form of very diverse: computer music, computer graphic arts, digital animation, holographic interactive installations, interactive digital film and television, interactive theater, virtual space art, web art, cinema machine, hypertext fiction and other forms of communication arts, it can be said to be contending.

In this era of aesthetic gradually sublimated, art itself becomes a historical phenomenon and cultural phenomenon variability. With the art of talking about gradually increased, while the art itself and constantly improve the impact of art on society as a whole is growing. Artistic soul always with a spirit of adventure, with its own strong visual power of sublimation in realistic and deny reality, it creates conform to the laws of the art virtual space. As a symbol of artistic impression and one from pure and simple aesthetic product, instinctively she gave birth to its own meaning and infinite nature. Gradually neglected basic principles of art, and have been gradually discarded evaluation criteria to please, said in today's aesthetic world, there is no unchanging pattern, this is the new media art to bring change, it is a new art categories, but also anti-traditional post-modern movement in art extends.

The first step is digital art foundation guides to study course. This course consists of three aspects, first, the basic theory and modeling art appreciation, art appreciation and the second is the basic theory of color, and the third is to appreciate the finished design basic theory. The course is designed to enable students to obtain works of art in general on the basis of theoretical knowledge from appreciating, that is, from the point, line, surface, color, light, and all other ornamental artistic quality of various schools of art, painting and design categories include shared vision based on the relationship between light and shadow to learn basics principles of modeling theory. Import new media art appreciation courses and courses from the visual element is because the new media art as a comprehensive arts an interdisciplinary, students aesthetic styling and image of aesthetic ability to learn this art form foundation.

New media art education needs to equip students with the color of the performance and the relationship between them. Its purpose is to train students of color analysis and appreciation. The third basic course is "finished appreciate design and basic theory." The focus here is designed by the appreciation of creativity, and guide students' creative thinking, which is the main new media art and design innovative idea. This course must instill a certain scientific knowledge while students humanities. Such as curriculum integration of certain design aesthetics, design history, sociology, media theory basis, and these constitute a framework of theoretical knowledge, combined with a large number of new media art appreciation courses. These students have the basic theory and the humanities and it can be a matter of course into their own concept of new media art, so it will not appear next on the basis of production across the curriculum and had a big problem.

The second step, new media art appreciation and basic production. This course focuses on the aesthetic is to improve students' understanding of the current system of new media art and to learn and master basic digital art. Digital art design is divided into screen digital design, animation design, the impact of streaming media creation, online media design. During this phase, by imitating the 
great new media art, try to figure out and gradually learn new media art production experience and common software. Hands-on practices in which interspersed courses allow students to learn from new media art practice and improve and improve their aesthetic ability. Also, you can organize different classes of students' interaction and cooperation, through such cooperation and exchanges enable students to improve each other, and common progress, better access to unexpected results.

The third step, new media art practice. Standardization of teaching two courses in front of the students understanding of the new media art is more profound and more solid theoretical foundation. But knowledge must also be teaching to the creation of digestion and inspection purposes in order to consolidate learning. Teachers encourage students to good design, not only to solve the problem of knowledge, but also focus on training students in the creative process of team understanding, this would also strengthen the largely student exchanges and presentation skills.

The new curriculum has created the birth of new talented artists, teachers found in the educational process, the more those in the past is considered to be "cross-border" student, the more we can create unique new media art. At the end of each semester when hall of this course organized by the exhibition held in the school on a regular basis using the most important events held their event attracted business people from outside the school, students and artists to participate. At the show, the students wearing the head of their own design data theft, gloves and other equipment on stage, on the big screen to the audience present their design to create "virtual world."

Of course, a number of conditions to limit the formation of "Art Team" in the traditional art of teaching, but in modern society, called for the creation and teamwork coexist together under the spirit of teachers in helping students to use creativity to achieve art methods, while more should be focus shifts to practical ability, ability to cooperate, exchange capacity of the integrated learning and exploration learning up.

\section{Conclusion}

New media art in the course of the development of traditional art teaching several twists and turns. From the initial confusion to modern design to this day as an independent category, we now see is the integration of new media art in its infancy middle school art education. New media art as a new discipline of information society, in order to Chinese education can cultivate talents with the world, and even more to adapt to the innovation consciousness and cultural awareness and thus modern society, the popularity of new media art education should be earlier and more science.

\section{Reference:}

[1] Liu Rude. Problem-based learning in primary and secondary schools to use. East China Normal University (Education Science Edition) [J], 2002.3

[2] Zhang Jian. The teaching mode and the value of art education of middle school. Chinese Art Education, 2006.

[3] Zhong Qijing. "Critical Thinking" and Its Teaching. Global Education [J], 2002.

[4] Zhu Ting. Strengthen boast local culture through art education awareness. Artistic Exploration [J], 2007. 